\title{
Electrically Small Folded Slot Antenna Utilizing Capacitive Loaded Slot Lines
}

\author{
Maximilian C. Scardelletti ${ }^{1}$, George E. Ponchak ${ }^{1}$, Shane Merritt ${ }^{2}$, John S. Minor ${ }^{1}$, and Christian A \\ Zorman $^{3}$
}

1. NASA Glenn Research Center, 21000 Brookpark Road, Cleveland, Ohio, 44135 USA

2. University of Iowa, Iowa City, Iowa

3. Case Western Reserve University, Cleveland, $\mathrm{OH} 44135$

\begin{abstract}
This paper presents an electrically small, coplanar waveguide fed, folded slot antenna that uses capacitive loading. Several antennas are fabricated with and without capacitive loading to demonstrate the ability of this design approach to reduce the resonant frequency of the antenna, which is analogous to reducing the antenna size. The antennas are fabricated on Cu-clad Rogers Duriod ${ }^{\mathrm{TM}}$ 6006 with multilayer chip capacitors to load the antennas. Simulated and measured results show close agreement, thus, validating the approach. The electrically small antennas have a measured return loss greater than $15 \mathrm{~dB}$ and a gain of 5.4, 5.6, and $2.7 \mathrm{dBi}$ at $4.3,3.95$, and $3.65 \mathrm{GHz}$, respectively.
\end{abstract}

Index Terms - Miniature Antenna, Capacitive Loading, Coplanar Waveguide, Folded Slot Antenna.

\section{INTRODUCTION}

The size of commercial, wireless products continues to shrink, and as they do so, the range of applications integrated within the package increases. Other applications such as implanted, wireless, biomedical sensors and wireless sensors embedded within engines and machinery must also be small so as not to harm the patient or interfere with the machines' operation. This demand for small size has created the need for the development of small antennas. However, the radiation efficiency, directivity, and impedance match of electrically small antennas is limited [1].

Various methods to reduce the size of printed antennas have been reported, with most of the methods relying on the loading of the antenna. A microstrip fed slot radiator was reactively loaded to arbitrarily reduce the length of the slot radiator without affecting the impedance match [2]; a gain of $-3 \mathrm{dBi}$ and a fractional bandwidth of 0.034 $\%$ were demonstrated for an antenna of $0.2 \times 0.2 \lambda_{0}$. A microstrip fed slot antenna with inductive and capacitive loading has been reported with 59\% size reduction [3], but gain was not reported. A microstrip fed circular slot antenna that is capacitively loaded was demonstrated with a $23 \%$ size reduction [4].
In this paper, a coplanar waveguide (CPW) fed folded slot antenna with capacitive loading is reported for the first time to the best of our knowledge. Electromagnetic simulations and measured return loss and radiation patterns are presented to demonstrate the reduction in the antenna operation frequency by $22 \%$ while maintaining a constant antenna size.

\section{ANTENNA DESIGN AND SIMULATIONS}

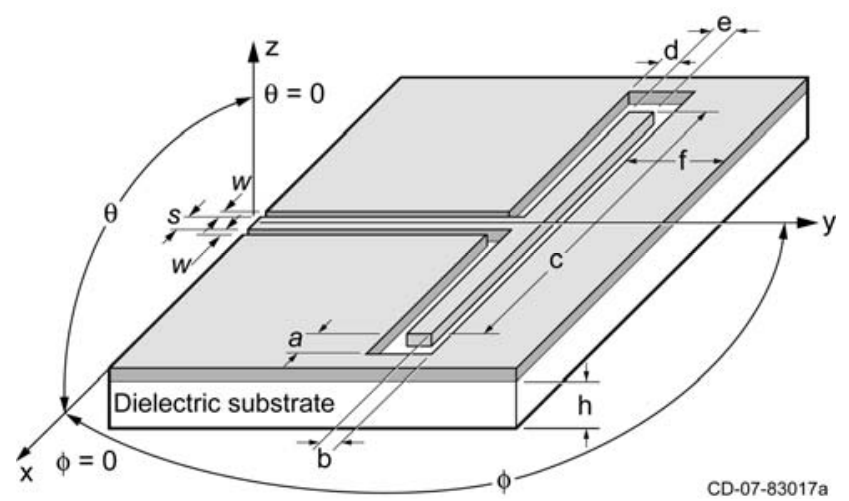

Figure 1: Schematic of standard CPW fed folded slot antenna.

A standard, CPW fed, folded slot antenna without capacitive loading is shown in Fig. 1. The antenna is comprised of a pair of slotline resonators that are folded such that they meet along the center line of the CPW. A virtual open circuit exists on the antenna where the slots meet at the y axis. The antenna is designed such that the mean path length of each of the folded slots is $\lambda_{0} / 2$ if the parasitic reactance due to the 90 degree bends and $\mathrm{T}$ junction is ignored. In the antennas presented here, the mean path length is $29 \mathrm{~mm}$, so a frequency of $5.2 \mathrm{GHz}$ is expected. The antenna dimensions, which are shown in Table 1, are optimized with High Frequency Structure Simulator (HFSS) [5] for a resonant frequency of $5 \mathrm{GHz}$ when fabricated on Rogers RT Duriod ${ }^{\mathrm{TM}} 6006$ with a 
dielectric constant of 6.15 , substrate thickness of 0.635 $\mathrm{mm}$ and a $34 \mu \mathrm{m}$-thick $(0.5 \mathrm{oz}$.) copper laminate on its top side (no ground plane). The antenna is fed by a CPW line with an $\mathrm{S}=2.3$ and $\mathrm{W}=0.3 \mathrm{~mm}$, which equates to a characteristic impedance $\left(\mathrm{Z}_{\mathrm{o}}\right)$ of approximately $50 \Omega$.

To decrease the frequency of optimum impedance match without changing the ground plane dimensions ( 29 X $40 \mathrm{~mm}^{2}$ ), mean path length, the antenna length $(\mathrm{c}+2 \mathrm{a}=27 \mathrm{~mm})$, or CPW dimensions, chip capacitors are added to the antenna as shown in Fig. 2. HFSS is used to optimize the folded slot antenna's remaining dimensions, which are listed in Table 1, for three antennas with capacitors of $0.1,0.3$, and $0.8 \mathrm{pF}$.

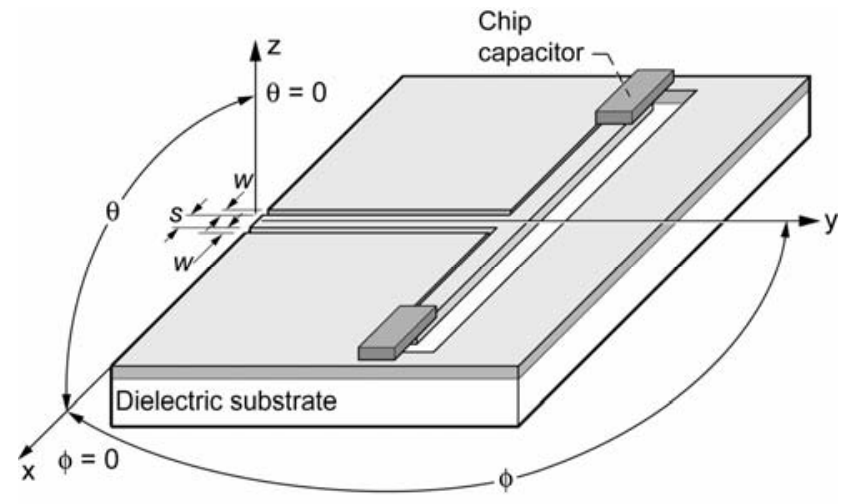

CD-07-83017c

Figure 2: Schematic of folded slot antenna with capacitor loading.

\section{MEASUREMENT PROCEDURES}

The antennas are fabricated on Rogers RT Duriod ${ }^{\mathrm{TM}}$ 6006 using standard lithography and copper etching. To facilitate measurements, a SMA to microstrip launcher adapted for $\mathrm{CPW}$ is soldered to the board. ATC 600F Series chip capacitors $(0.1,0.3$, and $0.8 \mathrm{pF})$ are used for loading the slot antennas. Larger capacitors could not be used because this required slots that are narrower than $0.25 \mathrm{~mm}$, which could not be etched with sufficient accuracy. The folded slot antennas with and without capacitive loading were characterized using an Agilent E8364B Precision Network Analyzer (PNA). A shortopen-load coaxial calibration is performed to place the calibrated reference plane at the SMA launcher.

The radiation patterns are measured in a far field chamber. The antenna gain is determined by using the substitution method with a known gain horn with a specified accuracy of $\pm 0.8 \mathrm{dBi}$.

\section{Simulated AND MEASUREd Results}

The simulated and measured reflection coefficient for the antennas without and with capacitors is shown in Fig.
3. It is seen that the antenna without capacitor was predicted to resonate at $5 \mathrm{GHz}$, but it actually resonated at 4.7 GHz. Other than this one case, the measured resonant frequency matches the simulated resonant frequency well. It is also seen that the $10 \mathrm{~dB}$ return loss fractional bandwidth decreases as the capacitor loading increases, from $15 \%$ without loading to $4.7 \%$ with the $0.8 \mathrm{pF}$ capacitor. The S-parameter results are summarized in Table 1. Although not shown, it is seen in Table 1 that the resonant frequency is decreased by changing the dimensions of the slots without changing the mean path length, but the impedance match is very poor, with only a $5 \mathrm{~dB}$ return loss. Thus, the loading capacitors perform two functions, they increase the electrical path length allowing the antenna to operate at a lower frequency and they improve the impedance match.

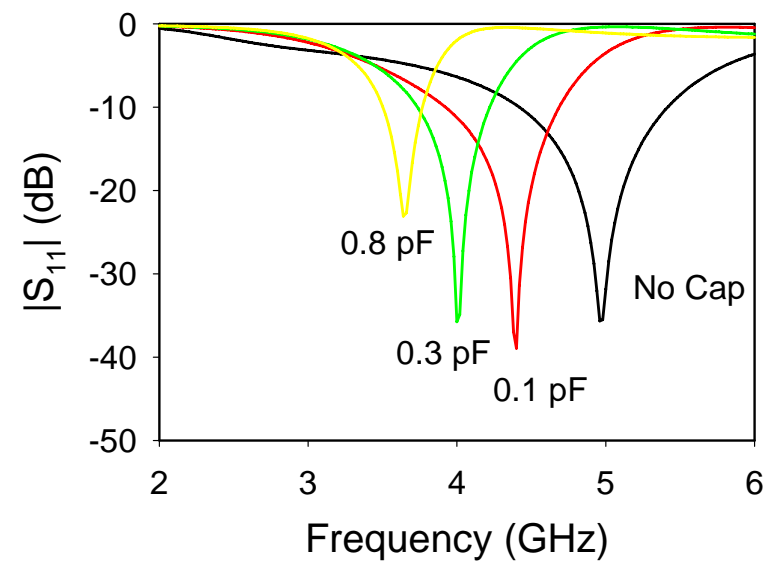

(a)

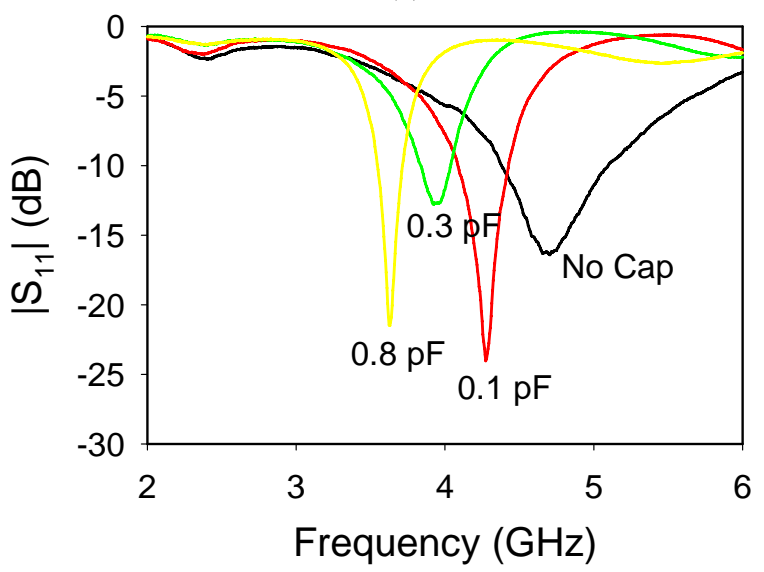

(b)

Figure 3: (a) Simulated and (b) measured $\left|\mathrm{S}_{11}\right|$ for antennas without and with capacitors.

The measured radiation patterns for the antennas are shown in Fig. 4. It is seen that for no capacitive loading and small capacitor loading, the agreement between measured and simulated is very good. For larger loading, 
the simulated H-plane pattern still shows a near omnidirectional pattern, whereas, the measured H-plane pattern has $15 \mathrm{~dB}$ nulls at \pm 90 degree. It is also seen that the cross-pol patterns increase in strength as the level of loading is increased. However, it is seen that the gain is not degraded as the loading is increased, maintaining a level close to $5 \mathrm{dBi}$ as the resonant frequency decreases from 4.7 to $3.7 \mathrm{GHz}$. These results are summarized in Table 1.

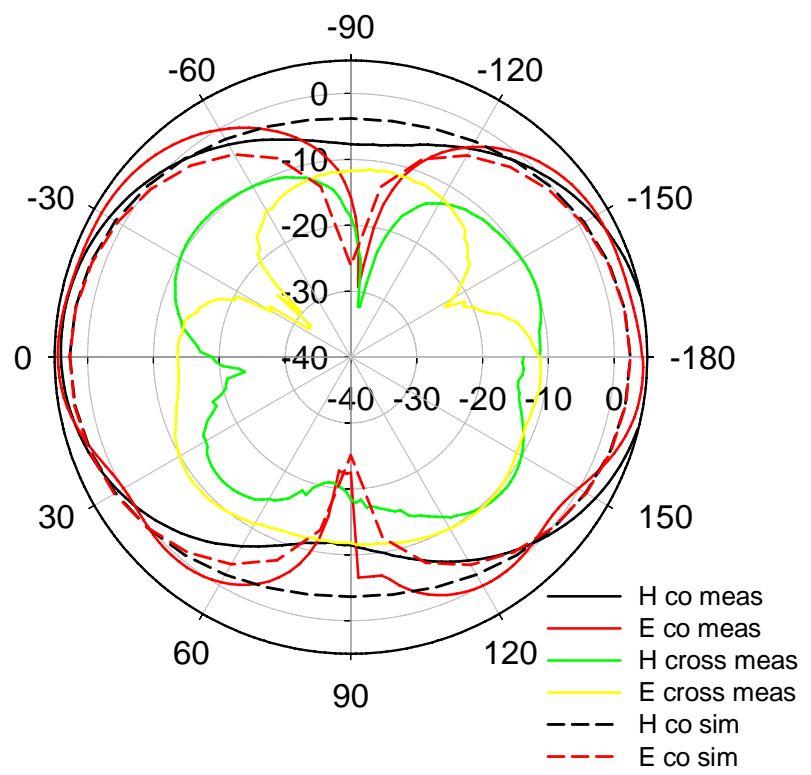

(a)

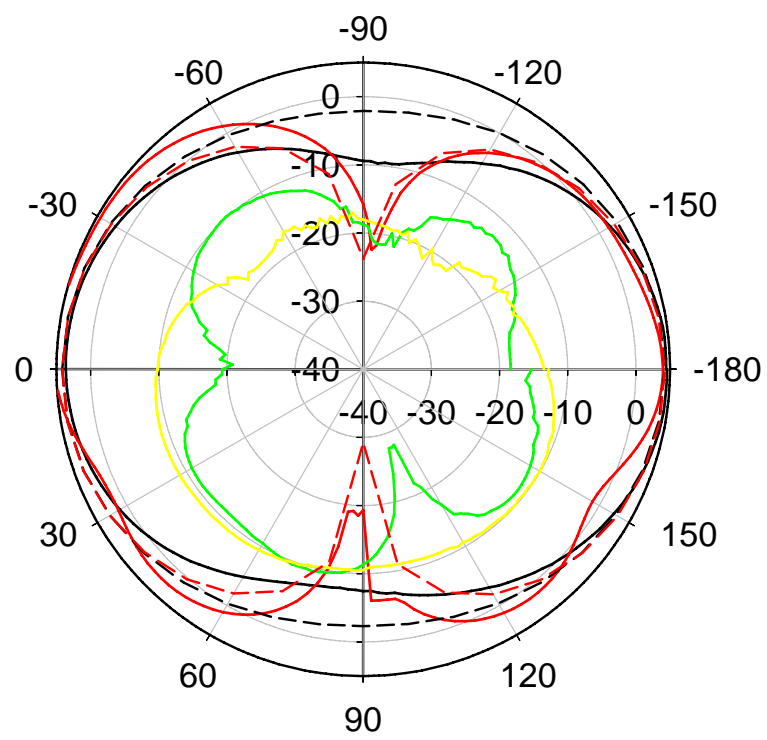

(b)

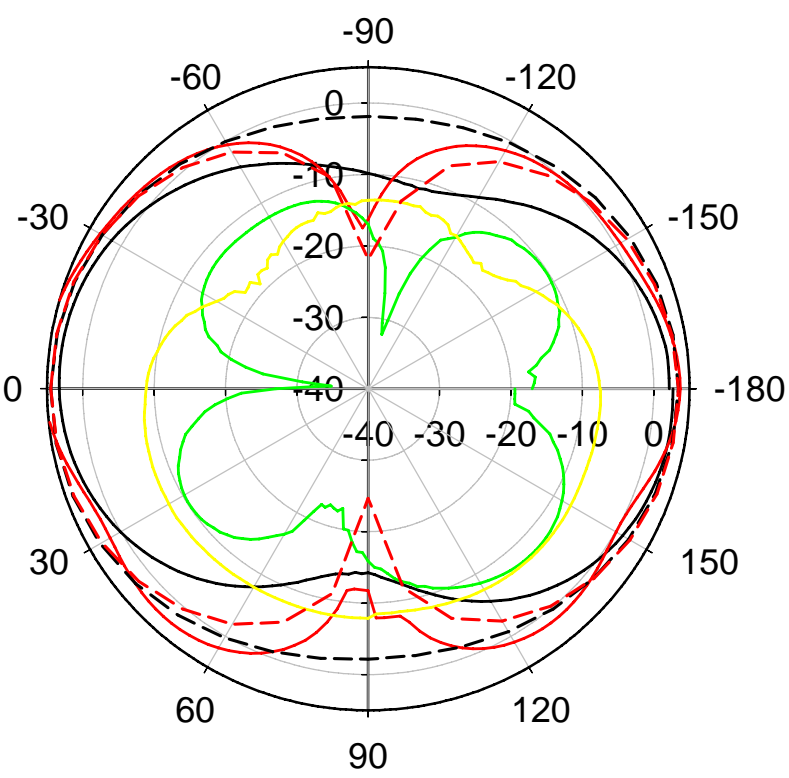

(c)

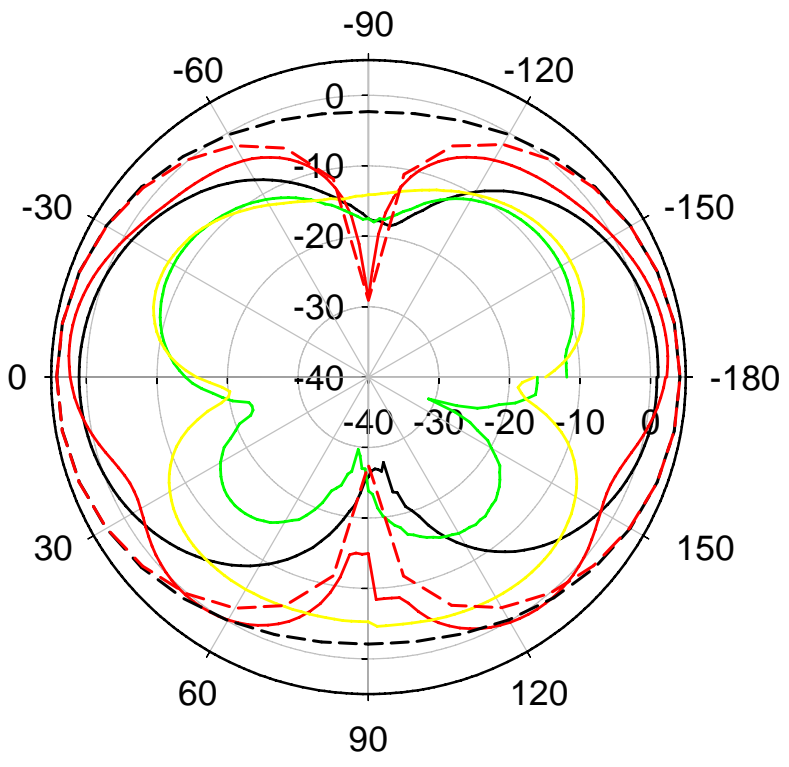

(d)

Figure 4: Measured and simulated radiation characteristics for (a) no capacitor, (b) $0.1 \mathrm{pF}$, (c) $0.3 \mathrm{pF}$, and (d) $0.8 \mathrm{pF}$ capacitors. (all plots in $\mathrm{dBi}$ )

\section{CONCLUSION}

Coplanar waveguide fed folded slot antennas may be loaded with capacitors at the midpoint of the two folded slots to reduce the frequency that the antenna is matched to $50 \Omega$. It is shown in this paper that a frequency reduction of $22 \%$ can be obtained without increasing the antenna size. This may be inverted and an antenna 
operating at a desired frequency may be reduced in size by $22 \%$. The gain of the antenna was not decreased significantly as the frequency is reduced, but the $10 \mathrm{~dB}$ return loss fractional bandwidth is reduced by a factor of 3. It is believed that this method may be extended further, and was only limited here due to the fabrication tolerance of the slots, which become narrower as the capacitive loading is increased.

\section{ACKNOWLEDGEMENT}

This work was funded by NASA as part of the Aeronautics IVHM high temperature wireless sensors program. We would like to thank Elizabeth McQuaid for fabrication expertise. We thank LERCIP High School Internship program and Undergraduate Student Research Program (USRP) for providing stipend support for Mr. Minor, a senior at Brush High School, Lyndhurst, $\mathrm{OH}$ and Mr. Shane Merrit from the University of Iowa. We also thank the NASA Glenn Faculty Fellowship Program for supporting Dr. Zorman an Associate Professor at Case Western Reserve University.

\section{REFERENCES}

[1] R. C. Hansen, "Fundamental limitations in antennas," Proceedings of the IEEE, Vol. 69, No. 2, pp. 170-182, Feb. 1981.

[2] R. Azadegan and K. Sarabandi, "A novel approach for miniaturization of slot antennas," IEEE Trans. Ant. and Prop., Vol. 51, No. 3, pp. 421-429, March 2003.

[3] M. C. Liang, Y. M. Chen, C. C. Huang, and W. S. Chen, "An electrically small impedance-matched microstrip antenna design." IEEE Antennas and Prop. Society Int. Symp., Vol. 4, pp. 38 - 41, June 16-21, 2002.

[4] Cheng-Shong Hong, "Small annular slot antenna with capacitor loading," Electronics Lett., Vol. 36, No. 2, pp. 110-111, Jan. 20, 2000

[5] High Frequency Structure Simulator (HFSS), User's manual, Ansoft Corp., Pittsburgh, PA, 1994.

Table 1: Antenna dimensions and summary of results.

\begin{tabular}{|c|c|c|c|c|c|c|c|c|c|}
\hline $\begin{array}{c}\mathrm{c} \\
(\mathrm{mm})\end{array}$ & $\begin{array}{c}\mathrm{e} \\
(\mathrm{mm})\end{array}$ & $\begin{array}{l}\mathrm{e}+2 \mathrm{~d} \\
(\mathrm{~mm})\end{array}$ & $\begin{array}{l}\text { Mean Path } \\
\text { Length } \\
(\mathrm{mm})\end{array}$ & $\mathrm{C}(\mathrm{pF})$ & $\begin{array}{c}\text { Fo } \\
(\mathrm{GHz})\end{array}$ & $\begin{array}{c}10 \mathrm{~dB} \text { BW } \\
(\%) \\
\text { (meas.) }\end{array}$ & $\begin{array}{c}10 \mathrm{~dB} \text { BW } \\
(\%) \\
(\text { sim. })\end{array}$ & $\begin{array}{l}\text { Gain } \\
(\mathrm{dBi}) \\
\text { (meas.) }\end{array}$ & $\begin{array}{l}\text { Gain } \\
\text { (dBi) } \\
\text { (sim.) }\end{array}$ \\
\hline 25 & 2.0 & 4.0 & 29 & & 4.7 & 15 & 20 & 5.3213 & 2.6629 \\
\hline 25 & 2.0 & 4.0 & 29 & 0.1 & 4.3 & 7.8 & 17 & 5.3510 & 4.2331 \\
\hline 26 & 2.0 & 3.0 & 29 & & 4.2 & & & 5.1298 & 4.7607 \\
\hline 26 & 2.0 & 3.0 & 29 & 0.3 & 3.95 & 5.1 & 12 & 5.5785 & 4.4457 \\
\hline 26.5 & 2.0 & 2.5 & 29 & & 4 & & & 4.1631 & 4.8590 \\
\hline 26.5 & 2.0 & 2.5 & 29 & 0.8 & 3.65 & 4.7 & 3 & 2.6387 & 4.2076 \\
\hline
\end{tabular}

